Revista Agrarian

ISSN: $1984-2538$

\title{
Características fisiológicas de mudas de Eucalyptus sp sob diferentes concentrações de potássio
}

\section{Physiological characteristics of seedlings of Eucalyptus sp under different concentrations of potassium}

\author{
Dinamar Prado Spíndola Mondini', Etenaldo Felipe Santiago, Omar Daniel, Joil Vilhalva Silva, \\ Nayara Spíndola Francisco
}

Universidade Estadual de Mato Grosso do Sul, UEMS, Brasil.E-mail: dinamarpsm@hotmail.com

Recebido em: 15/05/2015

Aceito em:29/05/2018

\begin{abstract}
Resumo: Conduziu-se este trabalho com o objetivo de avaliar as alterações fisiológicas de mudas de Eucalyptus grandis x Eucalypytus urophylla em função do enriquecimento potássico. As mudas com idade de $60 \mathrm{DAE}$, foram submetidas a diferentes concentrações de potássio $\left(0,250,500\right.$ e $\left.750 \mathrm{mg} \mathrm{L}^{-1}\right)$ por meio de solução nutritiva padrão administrada via sub-irrigação por período de 46 dias. A fonte utilizada foi cloreto de potássio e o delineamento experimental o inteiramente casualizado. Foram estudadas eficiência quântica $(F v / F m)$, dissipação não fotoquímica $(D I o / C S)$, densidade de moléculas do centro de reação $(R C / C S)$, taxa fotossintética $(A)$, transpiração $(E)$, eficiência intrínseca no uso de água $\left(E U A_{\text {intr }}\right)$, condutância estomática $(G s)$ e consumo de solução nutritiva diário/tratamento $(S N C)$. A adubação potássica proporcionou aumento na eficiência quântica, densidade de moléculas do centro de reação e $E U A_{\text {intr }}$, diminuição da transpiração, condutância estomática e taxa fotossintética. Os dados avaliados em conjunto, sugerem que a adubação potássica pode ser importante como forma de preparação das mudas para o estresse no pós-plantio.
\end{abstract}

Palavras-chave: condutância estomática, eficiência no uso da água, eficiência quântica, taxa fotossintética

Abstract: Led this work was to evaluate the physiological changes of seedlings of Eucalyptus grandis $\mathrm{x}$ Eucalypytus urophylla a function of potassium enrichment. The seedlings aged 60 DAE were subjected to different concentrations of potassium $\left(0,250,500\right.$ and $\left.750 \mathrm{mg} / \mathrm{L}^{-1}\right)$ administered by sub-irrigation during a period of 46 days. The source used was potassium chloride and a completely randomized experimental design. Were studied: Quantum efficiency $(F v / F m)$, non-photochemical dissipation $(D I o / C S)$, density of molecules in the reaction center $(R C / C S)$, photosynthetic rate $(A)$, transpiration $(E)$, efficient use water $\left(E U A_{\text {intr }}\right)$, stomatal conductance $(G s)$ and consumption of nutrient solution daily/treatment $(S N C)$. Potassium fertilization providing increased quantum efficiency, high density of molecules in the reaction center and $E U A_{\text {intr }}$, decreases in $E, G s$ and $A$. The data evaluated together, suggest that potassium fertilization may be important as a way of preparing seedlings for stress post-planting.

Keywords: photosynthetic rate feeding, quantum efficiency, stomatal conductance, water use efficiency

\section{Introdução}

O potássio ocupa o segundo lugar como nutriente exigido em maiores quantidades pelas plantas para funções metabólicas e de crescimento (Hsiao e Lauchli, 1986). É considerado o mais importante cátion na fisiologia vegetal (Raij, 1991) com diversas funções como participação em processos osmóticos, síntese de proteínas, abertura e fechamento dos estômatos, controle do $\mathrm{pH}$, afetando ainda a permeabilidade da membrana, alem de ativar cerca de 60 enzimas, destacando-se a ribulose-bisfosfato carboxilase /oxigenase (Rubisco), enzima chave no processo fotossintético (Malavolta et al., 1997, Morgan et al., 2014). Em plantas $C_{3}$, como o eucalipto, a maioria das proteínas dos cloroplastos são as RuBp carboxilase, cuja síntese é prejudicada quando $\mathrm{o} \quad \mathrm{K}$ está deficiente, respondendo rapidamente ao fornecimento deste nutriente (Marschner, 1995).

As alterações funcionais nas plantas pela aplicação de diferentes doses de potássio podem ser investigadas por meio de ferramentas não destrutivas envolvidas direta ou indiretamente ao processo fotossintético. Isso se faz necessário, não só pela redução de custos, mas por possivelmente contribuir para a diminuição das mortes de mudas 


\section{Revista Agrarian}

ISSN: 1984-2538

nos primeiros dias após o transplante, principalmente em períodos de seca. Nesse sentido, foram avaliados os efeitos das diferentes concentrações de potássio sobre as principais características fisiológicas de mudas de eucaliptos.

\section{Material e Métodos}

O trabalho foi realizado em casa de vegetação na Universidade Estadual de Mato Grosso do Sul (UEMS) em Dourados/MS no período de $16 / 01 / 2012$ a 08/03/2012. Os tratamentos consistiram em quatro concentrações de potássio $\left(0,250,500\right.$ e $\left.750 \mathrm{mg} \mathrm{L}^{-1}\right)$ tendo como fonte o cloreto de potássio $(\mathrm{KCl})$, correspondente respectivamente a $(0 ; 0,3 ; 0,6$ e 0,9$) \mathrm{g} \mathrm{L}^{-1} \mathrm{~K}_{2} \mathrm{O}$. O delineamento experimental foi o inteiramente casualizado, sendo cada tratamento constituído por 38 mudas clonais de Eucalyptus grandis $\mathrm{x}$ Eucalypytus urophylla, com idade em torno de 60 dias após a estaquia (DAE), sendo quatro repetições.

Submeteu-se as mudas aos respectivos tratamentos, por um período de 46 dias, por meio de solução nutritiva padrão, administrada via subirrigação (SILVA et al., 2004) e balanceada com as seguintes fontes e concentrações (nitrato de cálcio, $1 \mathrm{~g} \mathrm{~L}^{-1}$; sulfato de magnésio, $0,5 \mathrm{~g} \mathrm{~L}^{-1}$; MAP purificado, $0,14 \mathrm{~g} \mathrm{~L}^{-1}$; ácido bórico, $3 \mathrm{mg} \mathrm{L}^{-}$ 1; sulfato de cobre, $0,8 \mathrm{mg} \mathrm{L}^{-1}$; sulfato de manganês, 2,5 $\mathrm{mg} \mathrm{L}^{-1}$; sulfato de zinco, $1,5 \mathrm{mg} \mathrm{L}^{-}$ 1; quelado de $\mathrm{Fe}$ a $6 \%, 25 \mathrm{mg} \mathrm{L}^{-1}$; molibdato de sódio, $0,25 \mathrm{mg} \mathrm{L}^{-1}$ ) utilizando-se na preparação somente água destilada. Todas estas adubações foram recomendadas pelo Eng. ${ }^{\circ}$ Florestal Dr. Ronaldo Luiz Vaz de Arruda Silveira (RR Agroflorestal - Informe verbal).

Os tubetes ficaram sobre bandejas de polietileno (187 células) com pé, dispostas em cima de bandejas de PVC, contendo 7,0 L de solução, de maneira tal que apenas $3,0 \mathrm{~cm}$ da base dos tubetes permaneceram imersos na solução, o que permitiu a entrada no substrato por capilaridade. Trocaram-se as soluções a cada dois dias, evitando-se a proliferação demasiada de algas.

No quarto dia de tratamento iniciaram-se as leituras de: fluorescência máxima $(F m)$, fluorescência variável $(F v)$, eficiência quântica máxima do PSII $(F v / F m)$, densidade de moléculas dos centros de reação $(R C)$, energia de dissipação (DIo) (STRASSER, 2004), utilizando-se fluorímetro portátil Hansatech. Para leitura da condutância estomática, radiação fotossinteticamente ativa e temperatura da folha utilizou-se porômetro AP4 Delta T. Para obtenção da temperatura da folha utilizou-se da seguinte fórmula: $\Delta T=T_{\text {cup }}-T_{\text {leaf, }}$ (sendo $T_{\text {cup }}=$ temperatura da cabeça do sensor e $T_{\text {leaf }}$, $=$ temperatura da folha) conforme Verhoef (1997).

Todas essas leituras foram tomadas nas folhas do $4^{\circ}$ ao $7^{\circ}$ nó a partir do ápice em seis plantas do interior de cada repetição, evitando o efeito de borda, sendo coletadas entre 08:00 e 10:00 horas e repetidas a cada sete dias, até o término do experimento, totalizando 12 leituras. Para as leituras com fluorímetro, clipou-se uma folha por planta, por um período de trinta minutos, submetendo-as em seguida a um flash de 1.500 $\mu \mathrm{mol} \mathrm{m} \mathrm{m}^{-2} \mathrm{~s}^{-1}$ durante um segundo e imediatamente foram coletados os dados de fluorescência. Totalizando 15 plantas por tratamento por dia. As leituras com porômetro foram realizadas em 8 plantas por tratamento ao dia, totalizando 32 leituras diárias.

Para a medição da transpiração instantânea e taxa fotossintética líquida em mudas com 100 dias utilizou-se o aparelho LCi Portable Photosynthesis System, com esses dados foram estimadas a eficiência intrínseca do uso da água $\left(E U A_{\text {intr }}=A / E\right)$, conforme Ngugi et al. (2003a; $2003 \mathrm{~b} ; 2004)$. Sendo $\left(E U A_{\text {intr }}\right)$ quantidade de água transpirada para produção de certa quantidade de matéria seca produzida (SILVA et al., 2007), por meio da fixação de carbono. Foram realizadas duas leituras por plantas por parcela em três dias consecutivos das folhas expandidas superiores do terço médio das plantas. Foi mensurado manualmente o consumo em litros de solução nutritiva diária por tratamento $(S N C)$, utilizandose jarra volumétrica.

Os dados obtidos foram interpretados utilizando-se ANOVA one way sendo o teste de Tukey aplicado a posteriori para comparação das médias, considerou-se 1 e $5 \%$ de significância. Dados também foram submetidos à análise de regressão, o modelo foi escolhido com base na significância dos coeficientes de determinação $\left(\mathrm{R}^{2}\right)$ com auxílio do programa BIOESTAT 5.0.

\section{Resultados e Discussão}

Foi observado efeito do $\mathrm{K}$ nas variáveis: eficiência quântica, densidade de moléculas do 


\section{(-) \\ Revista Agrarian \\ ISSN: 1984-2538}

centro de reação e energia de dissipação (Tabela 1). Para eficiência quântica e densidade de moléculas do centro de reação ocorreram aumento até a adição de $250 \mathrm{mg} \mathrm{L}^{-1}$ de $\mathrm{K}$ em relação à concentração 0. Para a energia de dissipação observou-se redução até a concentração de $500 \mathrm{mg}$ $\mathrm{L}^{-1}$ de $\mathrm{K}$.

Tabela 1. Comparativo das médias das variáveis de fluorescência da clorofila $a$ para mudas de eucalipto sob diferentes concentrações de potássio. Dourados, UEMS, 2011

\begin{tabular}{lccc}
\hline & $F v / F m$ & Variáveis & \\
$\mathrm{K}\left(\mathrm{mg} \mathrm{L}^{-1}\right)$ & $0,829 \mathrm{~b}$ & $1243,760 \mathrm{~b}$ & $D I o / C S$ \\
\hline 0 & $0,834 \mathrm{a}$ & $1331,767 \mathrm{a}$ & $47,802 \mathrm{a}$ \\
250 & $0,832 \mathrm{ab}$ & $1303,429 \mathrm{ab}$ & $45,661 \mathrm{~b}$ \\
500 & $0,831 \mathrm{ab}$ & $1285,926 \mathrm{ab}$ & $46,262 \mathrm{~b}$ \\
750 & $\mathrm{ab}$ & $47,059 \mathrm{ab}$ \\
\hline
\end{tabular}

Médias seguidas de mesma letra em coluna não diferem estatisticamente entre si ao nível de $5 \%$. $F v / F m=$ eficiência quântica, $R C / C S$ $=$ densidade de moléculas dos centros de reação e $D I o / C S$ = energia de dissipação, $(C S)$ por seção transversal.

A avaliação da eficiência quântica do fotossistema II (FSII) obtida a partir da fluorescência da clorofila $a$, mostra o nível de excitação da energia que dirige à fotossíntese, possibilitando estimar a inibição ou o dano no processo de transferência de elétrons do FSII (Maxwell e Johnson, 2000).

Uma planta está com seu maquinário fotossintético intacto quando os valores de eficiência quântica variam entre 0,75 e 0,85 (Bolhàr-Nordenkampf et al., 1989), enquanto queda nestes valores reflete a presença de dano fotoinibitório nos centros de reação do FSII (Björkman e Demming, 1987).

A redução dos valores de eficiência quântica $(F v / F m)$ são descritos como resposta comum em plantas mantidas em condições sub ótimas, sendo promovida por diferentes fatores geradores de estresse. Neste estudo, a elevação desta variável pela adição de potássio reflete uma resposta de aumento na eficiência dissipatória de energia destinada aos processos fotoquímicos no FSII que culminam na síntese de agentes redutores. Mendes (2013) estudando mudas de eucalipto obteve resultado semelhante em $\mathrm{Fv} / \mathrm{Fm}$ sendo que esta elevou-se ao adicionar $\mathrm{K}$, quando comparado ao tratamento sem adição do mesmo.

O potássio é necessário em concentrações elevadas no interior das plantas a partir das fases iniciais de crescimento vegetativo, sendo que a alta concentração pode ajudar a suportar súbitos eventos ambientais, como frio, geada, chuvas de final de ciclo, tensões elevadas de sal e ondas de calor, além de estresse osmótico (Kant et al., 2002).
$\mathrm{A}$ adição de $\mathrm{K}$ promoveu a diminuição na $D I o / C S$, variável que expressa a energia dissipada por calor e fluorescência (dissipação não fotoquímica). Ao contrário, ou seja, aumentos nesta variável podem evidenciar estresses e perdas de eficiência fotossintética.

Nota-se que o acréscimo de potássio proporcionou aumento na $R C / C S$. Por serem estas que recebem elétrons das demais moléculas de clorofila (antena), as RC são consideradas moléculas chave. Estudando folhas de arroz, Panda et al. (2011) observaram aumentos na $R C / C S$ nas horas mais frescas do dia e decréscimo nas horas mais quentes. Porém, para $D I o / C S$ os mesmos autores citam que ocorreu o inverso: aumentou gradualmente com o aumento da intensidade de luz, atingindo valores mais altos nas horas mais quentes do dia.

Aplicando-se a regressão para $F v / F m, R C / C S$, $D I o / C S$ e $G s$, o modelo quadrático foi o que melhor se ajustou aos dados, sendo observado ponto máximo em $F v / F m \quad(0,8)$ e $R C / C S$ $(1325,105)$ e ponto mínimo em DIo $(45,76)$ e $G s$ $(249,075)$ nas respectivas concentrações 410,420 , 400 e $750 \mathrm{mg} \mathrm{L}^{-1}$ de K (Figura 1A, 1B, 1C e 1D).

$\mathrm{O}$ ajuste de regressão para a variável $F v / F m$ (Figura 1A) sugere que a dose de $\mathrm{K}$ aplicada é relevante para se observar seu efeito, o que pode explicar os resultados observados por Mendes et al. (2013) que não encontraram efeito utilizando a dose $200 \mathrm{mg} \cdot \mathrm{dm}^{-3}$ de $\mathrm{K}_{2} \mathrm{O}$. A redução de $F v / F m$ e $R C / C S$ (Figuras 1B) em doses superiores a 500 $\mathrm{g} / \mathrm{L}^{-1}$ de $\mathrm{K}$ evidencia a relação entre estas variáveis, condições sub ótimas estão normalmente associadas à redução de ambas 


\section{(2) \\ Revista Agrarian \\ ISSN: $1984-2538$}

embora a resposta seja dependente do genótipo estudado (Gao et al., 2014; Li et al., 2014).
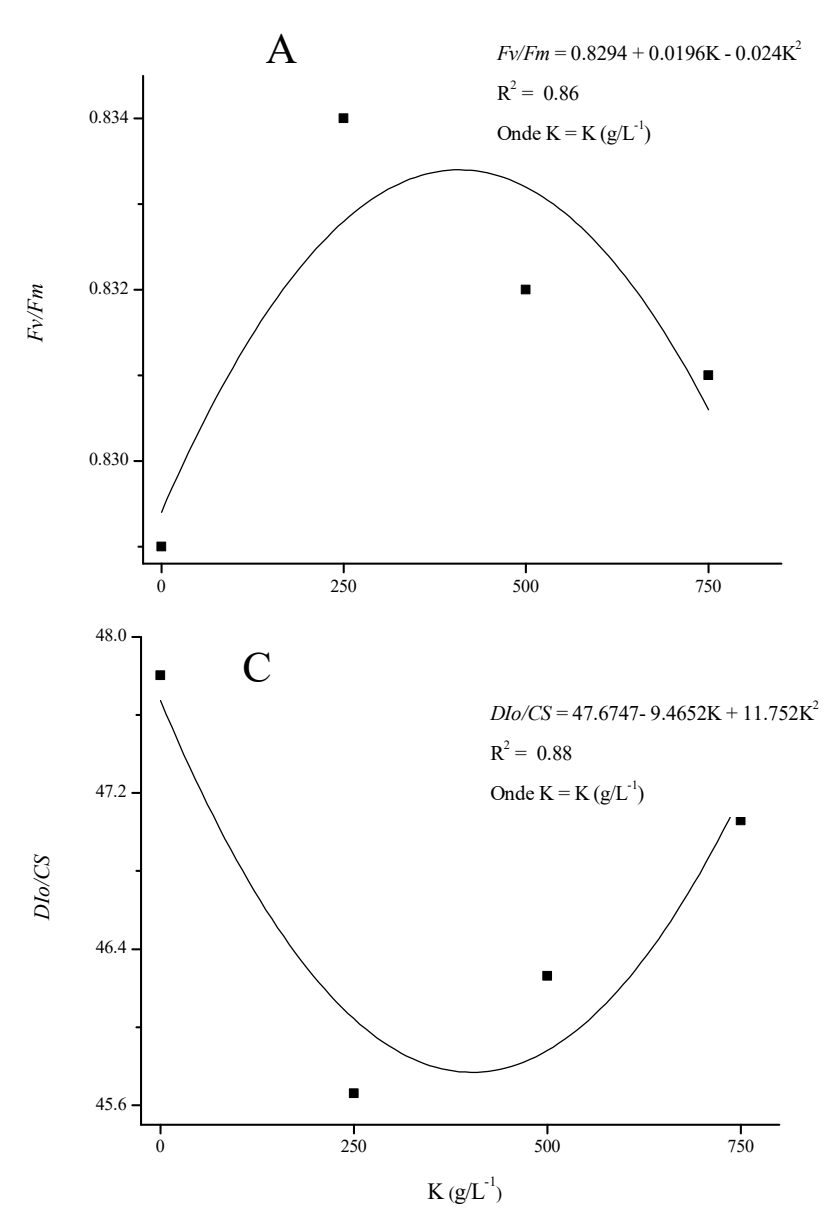

A variação de $D I o / C S$ em função da dose de $\mathrm{K}$ sugere menor dissipação não fotoquímica na dose $400 \mathrm{mg} \mathrm{L}^{-1}$ de $\mathrm{K}$, o que explicaria, em parte, os resultados de $F v / F m$ e $R C / C S$ nesta mesma dose.
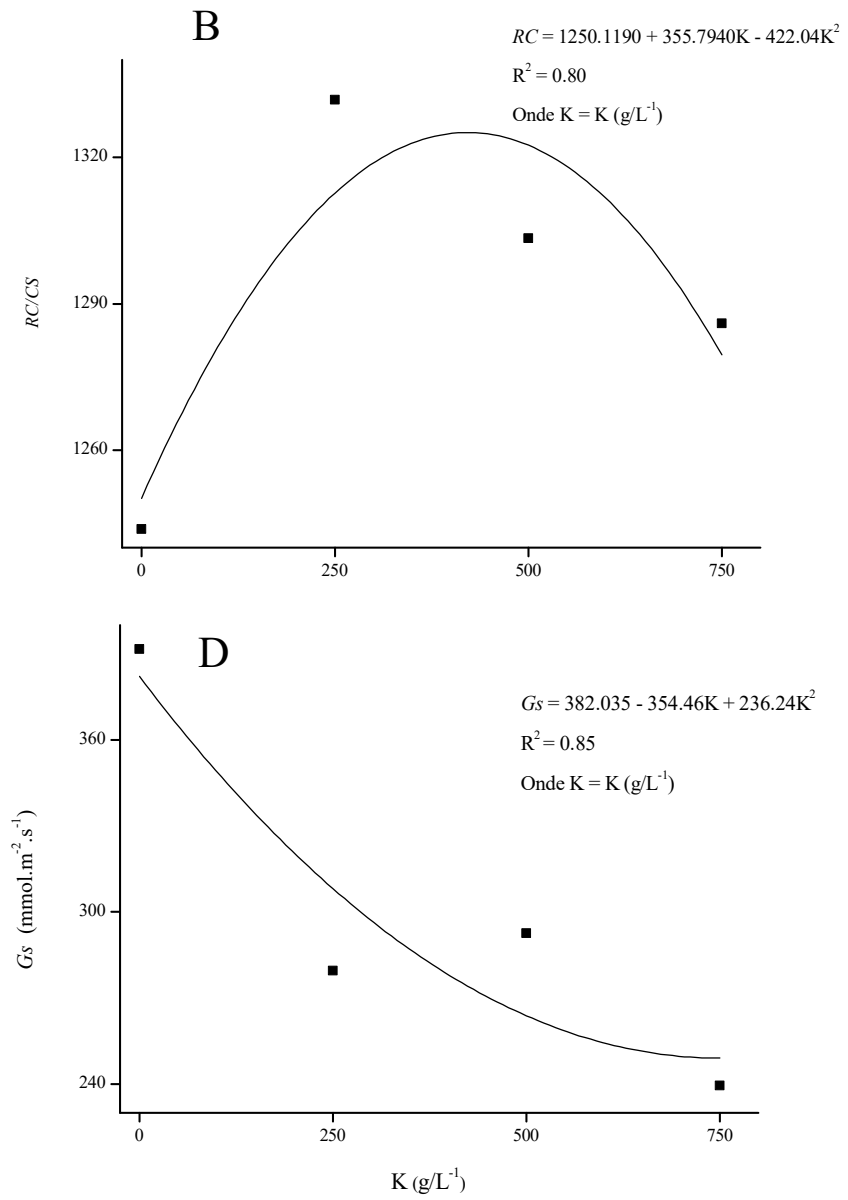

Figura 1. A - eficiência quântica $(F v / F m)$; B - densidade de moléculas dos centros de reação $(R C / C S)$ e C energia de dissipação $(D I o / C S)$ por seção transversal; D - condutância estomática $(G s)$ em mudas de eucaliptos sob diferentes concentrações de potássio. Dourados, UEMS, 2011.

As variações em $D I o / C S$ devem ser interpretadas com cuidado. Ferrante et al. (2011) estudando o efeito de borrifos salinos sobre plantas ornamentais verificaram para a maioria das espécies a redução de $R C / C S$ e aumentos em $D I o / C S$. Já Ecco et al. (2013) não verificaram variações na $D I o / C S$ em cana de açúcar sob diferentes regimes hídricos e doses de alumínio, ao passo que Meng et al. (2014) estudando os efeitos da aplicação de glucohexose em plantas de Cucumis sativus verificaram reduções em $\mathrm{DIo} / \mathrm{CS}$, aumento em $F v / F m$ e $R C / C S$, bem como redução em Gs. De qualquer modo, as mudanças na dissipação por calor podem ser influenciadas por diferentes fatores, espécies e cultivares, considerando-se ainda as respostas de ajuste verificadas numa mesma planta ou cultivar, o que reforça a idéia de que em nossos resultados, não foi possível correlacionar a energia não dissipada na forma de calor na dose $400 \mathrm{mg} \mathrm{L}^{-1}$ de $\mathrm{K}$ com aumentos nos processos fotoquímicos que tenham resultado em aumentos na taxa fotossintética.

Quanto às variáveis Gs, $T$ e $P A R$ (Tabela 2), observaram-se diferenças significativas na primeira variável, ou seja, a adição de $\mathrm{K}$ na concentração mais alta reduziu em $38,8 \%$ a 


\section{(ㄱ) \\ Revista Agrarian \\ ISSN: 1984-2538}

condutância estomática, corroborando com os dados obtidos na taxa transpiratória. Reduções nesta variável normalmente são explicadas pelo fechamento estomático promovido pela redução dos potenciais das células subsidiárias, seguido de perda de turgor nas células guarda. Também não se descarta possíveis sinalizações associadas ao efeito osmótico das soluções de cultivo.

Tabela 2. Comparação das médias da condutância estomática $(G s)$, temperatura da folha $(T=\Delta T)$ e radiação fotossinteticamente ativa $(P A R)$, em mudas de eucalipto sob diferentes concentrações de potássio. Dourados, UEMS, 2011

\begin{tabular}{cccc}
\hline Variáveis & $G s$ & $T$ & $P A R$ \\
$\mathrm{~K}\left(\mathrm{mg} \mathrm{L}^{-1}\right)$ & $\mathrm{mmol} \cdot \mathrm{m}^{-2} \cdot \mathrm{s}^{-1}$ & ${ }^{0} \mathrm{C}$ & $\mu \mathrm{mol}^{-2} \cdot \mathrm{s}^{-1}$ \\
\hline 0 & $391.58 \mathrm{a}$ & $27.51 \mathrm{a}$ & $226.91 \mathrm{a}$ \\
250 & $279.55 \mathrm{ab}$ & $27.73 \mathrm{a}$ & $226.39 \mathrm{a}$ \\
500 & $292.50 \mathrm{ab}$ & $27.56 \mathrm{a}$ & $234.83 \mathrm{a}$ \\
750 & $239.53 \mathrm{~b}$ & $27.79 \mathrm{a}$ & $246.80 \mathrm{a}$ \\
\hline
\end{tabular}

Médias seguidas de mesma letra em coluna não diferem estatisticamente entre si ao nível de 5\%.

A redução na condutância pode ser resultado da extrusão de malato das células-guarda, causando efluxo de $\mathrm{K}$ e, como consequência, o fechamento estomático (Shimazaki et al., 2007). Também podem ser influenciada pela ação do ácido abscísico (ABA), que induz o aumento do $\mathrm{Ca}^{+2}$ endógeno e simultaneamente o fechamento dos canais de influxo de $\mathrm{K}$ e indução dos canais de efluxo, culminando na rápida redução da pressão de turgor das células guarda e consequente fechamento estomático (Sasaki et al., 2010; Gu et al., 2012; Laanemets et al., 2012).

De maneira contrária aos resultados descritos no presente estudo, Mendes (2013) investigando a disponibilidade hídrica e adubação potássica em clones de eucalipto, verificou que a adição de $\mathrm{K}$ proporcionou maiores valores de Gs. Por outro lado, Silva et al. (2004) relacionando manejo hídrico versus doses de $\mathrm{K}$ em mudas de $E$. grandis, não observaram variação significativa entre as doses de K sobre a Gs. Chaves et al. (2004) verificaram que a $G s$ não sofreu influência em função do manejo hídrico, para estes autores mudas de eucalipto mantidas na capacidade de campo e mudas sob diferentes níveis de déficit hídrico apresentaram o mesmo comportamento.

Sob condições não limitantes de luz, altos valores de Gs implicam na abertura dos estômatos, permitindo não somente a saída do vapor como a difusão do gás carbônico para dentro da folha, a matéria-prima da fotossíntese. A Gs regula a taxa transpiratória por meio de diferenças de gradiente entre as células do mesófilo foliar e as célulasguarda dos estômatos (Eamus, 1999).

$\mathrm{A}$ adição de $\mathrm{K}$ mostrou efeito quadrático para $A, E$ e $E U A_{\text {intr }}$ (Figura 2A, 2B, 2C). Os pontos mínimos para taxa fotossintética $A(2,33)$ e transpiração $E(1,95)$ foram alcançados nas respectivas concentrações 540 e $560 \mathrm{mg} \mathrm{L}^{-1}$ de K. Para o ponto máximo em EUA $A_{\text {intr }}(1,21)$ na concentração de $1.120 \mathrm{mg} \mathrm{L}^{-1}$ de $\mathrm{K}$, valor este acima da concentração máxima utilizada neste trabalho. Observa-se que o $\mathrm{K}$ promoveu diminuição da taxa fotossintética e transpiração, sendo ambas as respostas concordantes com a diminuição na condutância estomática mostrada na Tabela 2. 


\section{(-)}

\section{Revista Agrarian}

ISSN: 1984-2538
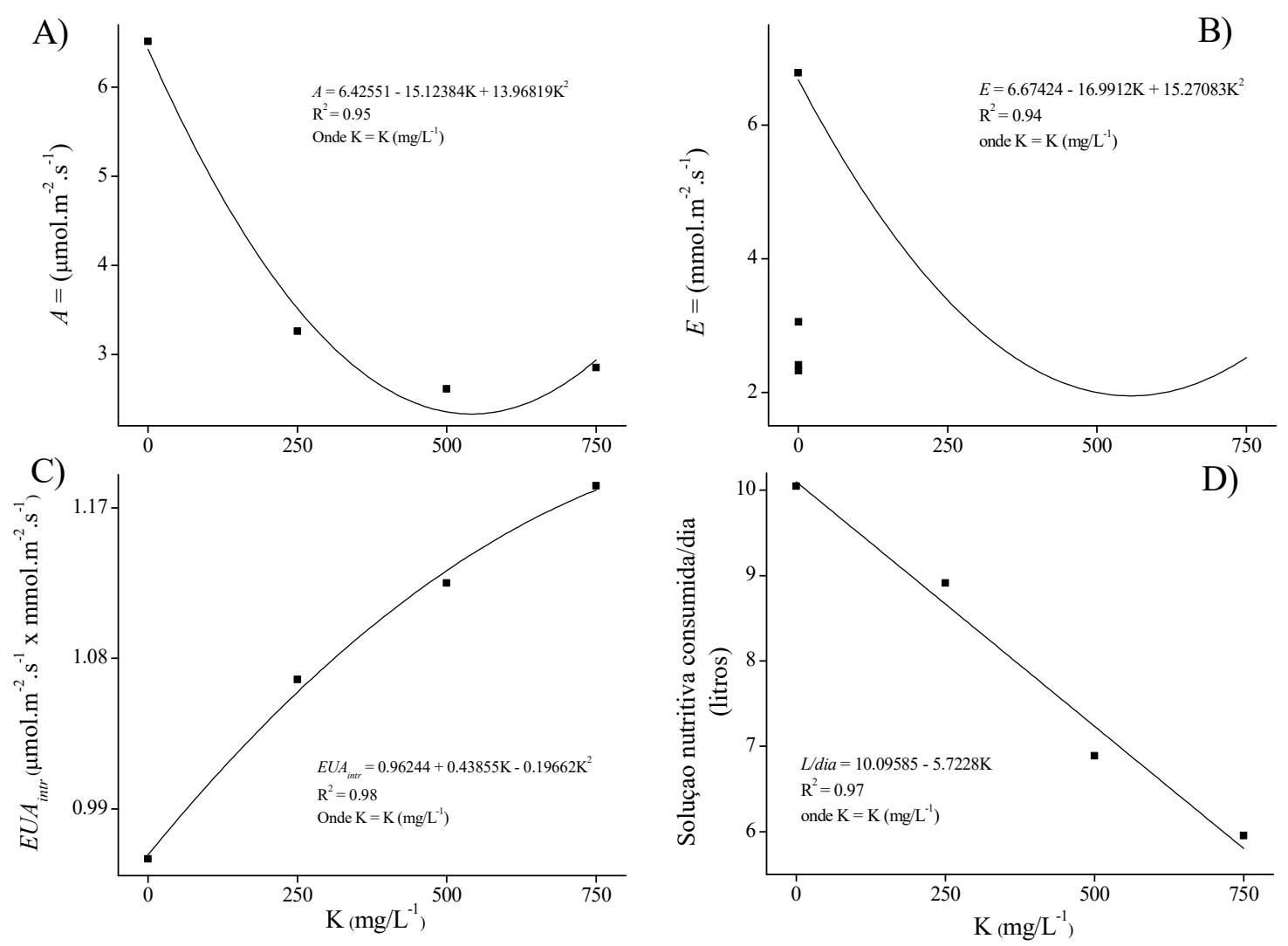

Figura 2. Taxa fotossintética $(A)$, transpiração $(E)$, eficiência intrínseca do uso da água $\left(E U A_{\text {intr }}=A / E\right)$ e solução nutritiva consumida/dia $(S N C)$, para mudas de eucaliptos mantidas em solução nutritiva com diferentes concentrações de potássio. Dourados, UEMS, 2011.

Os maiores valores de $A$ também foram induzidos pela maior $G s$, corroborando com Melo et al. (2009), em estudo com bananeiras submetidas à fertirrigação com diferentes concentrações de potássio e nitrogênio. $\mathrm{O}$ fechamento estomático impediu a saída da molécula de água da folha para o ambiente externo. Tal resultado tem efeito importante na refrigeração foliar (NOBEL, 1991) e na assimilação de nutrientes minerais (MARSCHNER, 1995), pois o fechamento estomático causa elevação na temperatura foliar e diminuição na absorção de nutrientes. A fotossíntese é limitada, não somente devido ao fechamento estomático, e consequente diminuição da difusão de $\mathrm{CO}_{2}$ para dentro da folha, mas também, pelo efeito do sal sobre os cloroplastos (LARCHER, 2000; TAIZ e ZEIGER, 2004).

A $E U A_{i n t r}=A / E$ é caracterizada como a quantidade de água transpirada para a produção de certa quantidade de matéria seca produzida (SILVA et al., 2007) por meio da fixação de carbono. Assim a EUA intr por uma planta pode ser entendida como eficiente mecanismo de evolução adaptativa por meio do qual esta adquire maior versatilidade para enfrentar possíveis déficits hídricos (LIMA, 1995).

O maior controle no fechamento estomático pode ser positivo quando implicar em redução na $E$, sem alterações significativas em $A$, considerando a razão entre estas duas variáveis, isto implicaria no aumento da $E U A_{\text {intr. }}$. Neste estudo, o potássio reduziu a taxa transpiratória, sendo esta condição favorável às mudas e apesar da redução ocorrida na taxa fotossintética, a eficiência quântica não foi reduzida e a $E U A_{\text {intr }}$ não diminuiu.

Para a variável $S N C$ (Figura 2D) o potássio proporcionou diminuição no consumo de solução, proporcional à adição deste nutriente, possivelmente porque plantas adequadamente supridas com $\mathrm{K}$ melhoram a regulação na abertura estomática, diminuindo quando necessário a $G s$ e consequentemente diminuindo também as perdas de água por transpiração, refletindo no aumento da EUA. 


\section{(2) \\ Revista Agrarian \\ ISSN: 1984-2538}

\section{Conclusão}

A adubação potássica foi positiva para eficiência quântica, densidade de moléculas do centro de reação e dissipação não fotoquímica, pois favorecem a terminação das mudas na fase que antecede o transplante, sendo a melhor concentração para estas características de 400 a $420 \mathrm{mg} \mathrm{L}^{-1}$ de $\mathrm{K}$.

A concentração de $560 \mathrm{mg} \mathrm{L}^{-1}$ de $\mathrm{K}$ promoveu a mínima transpiração, sendo fator efetivo para o aumento da eficiência no uso de água.

\section{Agradecimentos}

À Fibria/MS pela concessão do material genético e adubos químicos e à Coordenação de Aperfeiçoamento de Pessoal de Nível Superior (CAPES) pela concessão de bolsa.

\section{Referências}

CHAVES, J. H.; REIS, G. G. D.; REIS, M. D. G. F.; NEVES, J. C. L.; PEZZOPANE, J. E. M.; POLLI, H. Q. Seleção precoce de clones de eucalipto para ambientes com disponibilidade diferenciada de água no solo: relações hídricas de plantas em tubetes. Revista Árvore, v. 28, n. 3, p. 333-341, 2004.

EAMUS, D. Ecophysiological traits of deciduous and evergreen woody species in the seasonally dry tropics. Trends in Ecology and Evolutions. London, v.14, n.1, p.11-16, 1999.

ECCO, M.; SANTIAGO, E. F.; LIMA, P. R. Chlorophyll a fluorescence in two varieties of sugar cane subjected to aluminum and water stress. African Journal of Agricultural Research, v. 8, n. 39, p. 4941-4948, 2013.

FERRANTE, A.; TRIVELLINI, A.; MALORGIO, F.; CARMASSI, G.; VERNIERI, P.; SERRA, G. Effect of seawater aerosol on leaves of six plant species potentially useful for ornamental purposes in coastal areas. Scientia Horticulturae, v. 128, n. 3, p. 332-341, 2011.

GAO, P. P.; ZHENG, G. H.; WU, Y. H.; LIU, P. Effect of Exogenous Potassium on Photosynthesis and Antioxidant Enzymes of Rice under Iron
Toxicity Russian Journal of Plant Physiology, 2014, Vol. 61, No. 1, p. 47-52.

HSIAO, T.; LAUCHLI, A. Role of potassium in plant-water relations. Advances in Plant Nutrition, Connecticut, v. 2, p. 281-312, 1986.

KANT, S.; KAFKAFI, U. Potassium and abiotic stresses in plants. Potassium for sustainable crop production, p. 233-251, 2002.

LARCHER, W. Ecofisiologia vegetal. São Carlos: RiMa Artes e Textos, 2000. 531p.

Li, L.; Li, X. Y.; Xu, X. W.; Lin, L. S.; Zeng, F. J. Effects of high temperature on the chlorophyll a fluorescence of Alhagi sparsifolia at the southern Taklamakan Desert. Acta Physiologiae Plantarum, v. 36, n. 2, p. 243-249, 2014.

LIMA, W. P. Impactos da cultura do eucalipto. Revista Silvicultura, n. 64, p. 32-8, 1995.

MALAVOLTA, E.; VITTI, G. C.; OLIVEIRA, S. A. Avaliação do Estado Nutricional das Plantas: princípios e aplicações. 2. ed. Piracicaba: Associação Brasileira para a Pesquisa da Potassa e do Fosfato, 319 p. 1997.

MAXWELL, K.; JOHNSON, G. N. Chlorophyll fluorescence: a practical guide. Journal of Experimental Botany, v. 51, n. 345, p. 659-668, 2000.

MARSCHNER, H. Mineral Nutrition of Higher Plants. San Diego: Academic Press, 1995. 888p. MELO, A. S. DE; JUNIOR, C. D. da S.; FERNANDES, P. D.; SOBRAL, L. F.; BRITO, M. E. B.; DANTAS, J. D. M. Alterações das características fisiológicas da bananeira sob condições de fertirrigação. Ciência Rural, v. 39, n. 3, mai-jun, 2009.

MENDES, H. S. J.; DE PAULA, N. F.; SCARPINATTI, E. A.; PAULA, R. C. Respostas fisiológicas de genótipos de Eucalyptus grandis $\mathrm{X}$ Eucalyptus urophylla à disponibilidade hídrica $\mathrm{e}$ adubação potássica. Cerne, Lavras, v. 19, n. 4, p. 603-611, out./dez. 2013.

MENG, X.; GONG, Y.; FAN, H.; YU, Y. Photosynthesis regulation by glucohexaose through redox changes in Cucumis sativus. 


\section{(2) \\ Revista Agrarian \\ ISSN: 1984-2538}

Journal of Plant Growth Regulation. 33:571578, 2014.

MORGAN, S. H.; MAITY, P. J.; GEILFUS, C.; LINDBERG, S.; MÜHLING, K. H. Leaf ion homeostasis and plasma membrane Hp-ATPase activity in Vicia faba change after extra calcium and potassium supply under salinity. Plant Physiology and Biochemistry, 82, p. 244-253, 2014.

NGUGI, M. R. et al. Effects of soil water availability on water use efficiency of Eucalyptus cloeziana and Eucalyptus argophloia plants. Australian Journal of Botany, Camberra, v. 51, p. $159-166,2003$ b.

NGUGI, M. R.; HUNT, M. A.; DOLEY, D.; RYAN, P.; DART, P. Dry matter production and allocation in Eucalyptus cloeziana and Eucalyptus argophloia seedlings in response to soil water deficits. New Forests, West Lafayette, v. 26, p. 187-200, 2003a.

NGUGI, M. R.; DOLEY, D.; HUNT, M. A.; RYAN, P.; DART, P. Physiological responses to water stress in Eucalyptus cloeziana and Eucalyptus argophloia seedlings. Trees, Berlin, v. 18, p.381-389, 2004.

NOBEL, P. S. Physicochemical and environmental plant physiology. San Diego: Academic Press, 635 p. 1991.

PANDA, D. Diurnal variations in gas exchange and chlorophyll fluorescence in rice leaves: the cause for midday depression in $\mathrm{CO} 2$ photosynthetic rate. Journal of Stress Physiology \& Biochemistry, v. 7, n. 4, p. 175-186, 2011.

RAIJ, B. V. Fertilidade do Solo e Adubação. Piracicaba: Editora Agronômica Ceres, 1991. $343 p$.

SASAKI, T.; MORI, I. C.; FURUICHI, T.; MUNEMASA, S.; TOYOOKA, K.; MATSUOKA, K.; MURATA, Y.; YAMAMOTO, Y. Closing plant stomata requires a homolog of an aluminum-activated malate transporter. Plant and cell physiology, v. 51, n. 3, p. 354 - 365, 2010.

SHIMAZAKI, K. I.; DOI, M.; ASSMANN, S. M.; KINOSHITA, T. Light regulation of stomatal movement. Annual Review of Plant Biology, Palo Alto, v. 58, p. 219-247, 2007.

SILVA, A. A.; SILVA, J. F. Tópicos em manejo de plantas daninhas. Viçosa, MG: Universidade Federal de Viçosa, p. 189-248, 2007.

SILVA, M. R.; KLAR, A.; PASSOS, J. R. Efeitos do manejo hídrico e da aplicação de potássio nas características morfofisiológicas de mudas de Eucalyptus grandis W (Hill ex. Maiden). Irriga, v. 9, n. 1, p. 31- 40, 2004.

STRASSER, A.; TSIMILLI-MICHAEL, M.; SRIVASTAVA, A. Analysis of the fluorescence transient, in: Papageorgiou, G. C.; Govindjee, Chlorophyll fluorescence: A signature of photosynthesis. Advances in Photosynthesis and Respiration Series. Springer, Dordrecht, p. 32-362, 2004.

TAIZ, L.; ZEIGER, E. Fisiologia vegetal. 3. ed. Porto Alegre-RS: Artmed. 2004. 719 p.

VERHOEF, A. The effect of temperature differences between porometer head and leaf surface on stomatal conductance measurements. Plant, Cell \& Environment, v.20, n.5, p. 641-646, 1997. 